\title{
Editorial
}

\section{A Rollercoaster Plunge into 2022}

\author{
Gregory Y. H. Lip ${ }^{1,20}$ Anne Rigby ${ }^{3}$ Christian Weber $3,4,5$
}

${ }^{1}$ Liverpool Centre for Cardiovascular Science, University of Liverpool and Liverpool Heart \& Chest Hospital, Liverpool, United Kingdom

${ }^{2}$ Department of Clinical Medicine, Aalborg University, Aalborg, Denmark

3 Institute for Cardiovascular Prevention (IPEK), LMU Munich, Munich, Germany

${ }^{4}$ German Centre for Cardiovascular Research (DZHK), partner site Munich Heart Alliance, Munich, Germany

${ }^{5}$ Department of Biochemistry, Cardiovascular Research Institute Maastricht (CARIM), Maastricht University Medical Centre, Maastricht, The Netherlands

Thromb Haemost 2022;122:1-4.

At the same time last year we were very much hoping that the extraordinary research and clinical efforts deployed in response to the pandemic outbreak would mean that we would have stepped out of the rollercoaster wagon this year. ${ }^{1}$ But here we are in early 2022: the roller coaster elevating again ready for the next vertical plunge. On this ride, however, we came over unprecedented challenges and worldwide scientific collaboration towards vaccine development was accomplished at a speed and efficiency never imaginable so far. As it became evident thrombosis is playing an intrinsic part of COVID-19, our scientific community naturally fully engaged in this race against the disease. In this New Year Editorial, we reflect back on this rollercoaster year, which 2021 has presented to us all, and project ourselves into the New Year 2022.

As in $2020,{ }^{2}$ we have continued to receive a high proportion of COVID-19-related submissions in 2021, which translated in many COVID-19 publications as reflected in the Editor's Choice published in this issue. ${ }^{3}$ As always, we are indebted to our production team as well as our highly reactive reviewers and Editors who have responded to the urgent characteristic of the data and ensured fast track publications without neglecting less urgent but nonetheless fundamental findings.

We are pleased that our impact factor has risen to 5.723 for 2020, meaning Thrombosis and Haemostasis (T\&H) now ranks 10th out of 65 in the peripheral vascular disease category. Our percentile index in the hematology and peripheral vascular disease category which reflects the impact of T\&H in comparison to others in the field has also risen to $85 \%$. We continue to serve as a link journal for the European
Address for correspondence Gregory Y. H. Lip, MD, Liverpool Centre for Cardiovascular Science, University of Liverpool, William Henry Duncan Building, 6 West Derby Street, Liverpool L7 8TX, United Kingdom (e-mail: gregory.lip@liverpool.ac.uk).

Christian Weber, MD, Institute for Cardiovascular Prevention, LMU Munich, Pettenkoferstrasse 9, 80336 Munich, Germany (e-mail: chweber@med.Imu.de).

Society of Cardiology Working Groups on Thrombosis and on Atherosclerosis and Vascular Biology, as well as being the official journal of the Society of Thrombosis and Haemostasis Research (GTH), the Spanish (SETH) Society on Thrombosis and Haemostasis, and the Australian Vascular Biology Society (AVBS).

\section{Reviewers}

We are very grateful to our near 900 dedicated referees with whom we count on to complete our editorial work thoroughly.

We have to particularly praise our top 10 reviewers for 2021:

- Luis Jara-Palomares

- Erik Klok

- Stefano Barco

- Anetta Undas

- Young-Hoon Jeong

- Daniele Pastori

- Maria Elisa Mancuso

- Hideo Wada

- Shinichi Goto

- Michael Makris

\section{Section Editors}

We have been very lucky to rely on the expertise and dedication from 70 section editors last year. We bid farewell to Daniel Aradi (Hungary), John Eikelboom (Canada), Andras Gruber (United States), Francois Mach (Switzerland), Joao received

December 7, 2021

accepted

December 7, 2021 (c) 2022. Thieme. All rights reserved. Georg Thieme Verlag KG,

Rüdigerstraße 14,

70469 Stuttgart, Germany
DOI https://doi.org/ $10.1055 / \mathrm{s}-0041-1741073$. ISSN 0340-6245. 
Morais (Portugal), and Agneta Siegbahn (Sweden). We thank them for these past years when we have been able to count on their dedicated expertise and look forward to future collaborations and interactions.

We also give a warm welcome to our new colleagues on the Editorial Board: Gemma Vilahur Garcia (Spain) and Surakit Nathisuwan (Thailand), who have joined us as new section editors. We are very pleased that the geographical distribution of our Section Editors is increasingly spanning across the globe (-Fig. $\mathbf{1}$ ) and are looking forward to broadening the geographical scope of our Editorial Team further.

A special thank you goes to our last year's 10 most proactive section editors:

- Job Harenberg

- Sam Schulman

- Francesco Violi

- Andreas Greinacher

- Deirdre Lane

- Ramón Lecumberri

- Shinya Goto

- John Eikelboom

- Jeffrey Weitz

- Vera Ignjatovic

\section{What's New?}

\section{Accepted Manuscript Service Now Available for TH Open}

We introduced "Accepted manuscripts" in our last year Editorial. ${ }^{1}$ T\&H has indeed been pleased to offer authors and readers the possibility to publish and read manuscripts almost upon acceptance. The new scheme has been very welcome as shown by the high numbers of authors who chose it upon submission. We are delighted that this service is now also available for TH Open. Our readers are therefore able to enjoy reading articles from $\mathrm{T} \& \mathrm{H}$ as well as TH Open in a timely manner, which has proven particularly useful in the current pandemic emergency setting.

\section{Visual Summaries}

In 2020, we introduced optional "Visual Summaries" to convey the main message of the manuscript in a clear and concise graphic manner so that readers can grasp its contents and relevance at a glance. In the past two years, we have received an increasing number of such graphical abstracts which greatly improved the reading quality of the articles published $^{4-38}$ some of which have even been selected for the T\&H Issue Cover ${ }^{4,5,11,15,33,38}$ (-Fig. 2).

We are looking forward to seeing more from these eye catchers, as they will now become mandatory in 2022 and to displaying them in the online Table of Content and social media, to further attract and engage readers with article contents.

\section{Mini Series}

In addition to our traditional Theme Issues, we are excited to introduce two sets of "Mini Series" this year. One of these will consist of "state-of-the-art mini reviews" on a broad range of clinical and basic research topics. We are very grateful for this collaborative effort from our Section Editors who have actively responded to our survey and brought forward timely topics to encapsulate. The other one named "Clinical Concepts in Thrombosis," will encompass short discussions on controversial clinical concept issues by experts in the field. We are very much looking forward to publishing these successively in the coming 2022 issues.

Together with the entire editorial team including Elinor Switzer (Stuttgart), and Thieme Publisher (Stuttgart), we would again like to sincerely thank you, for contributing to the quality of our journal, whether it is by engaging in

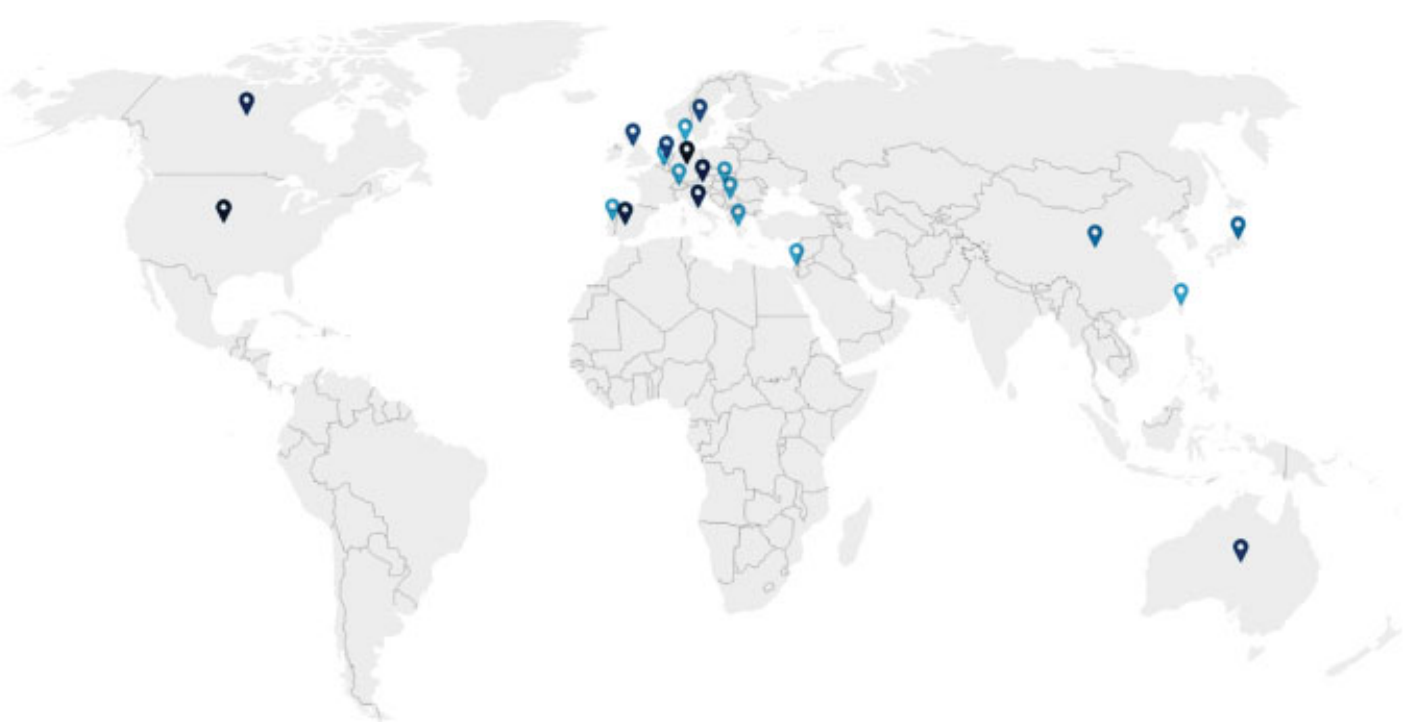

Fig. 12021 geographical distribution of Section Editors at Thrombosis and Haemostasis. Map created with Datawrapper. 

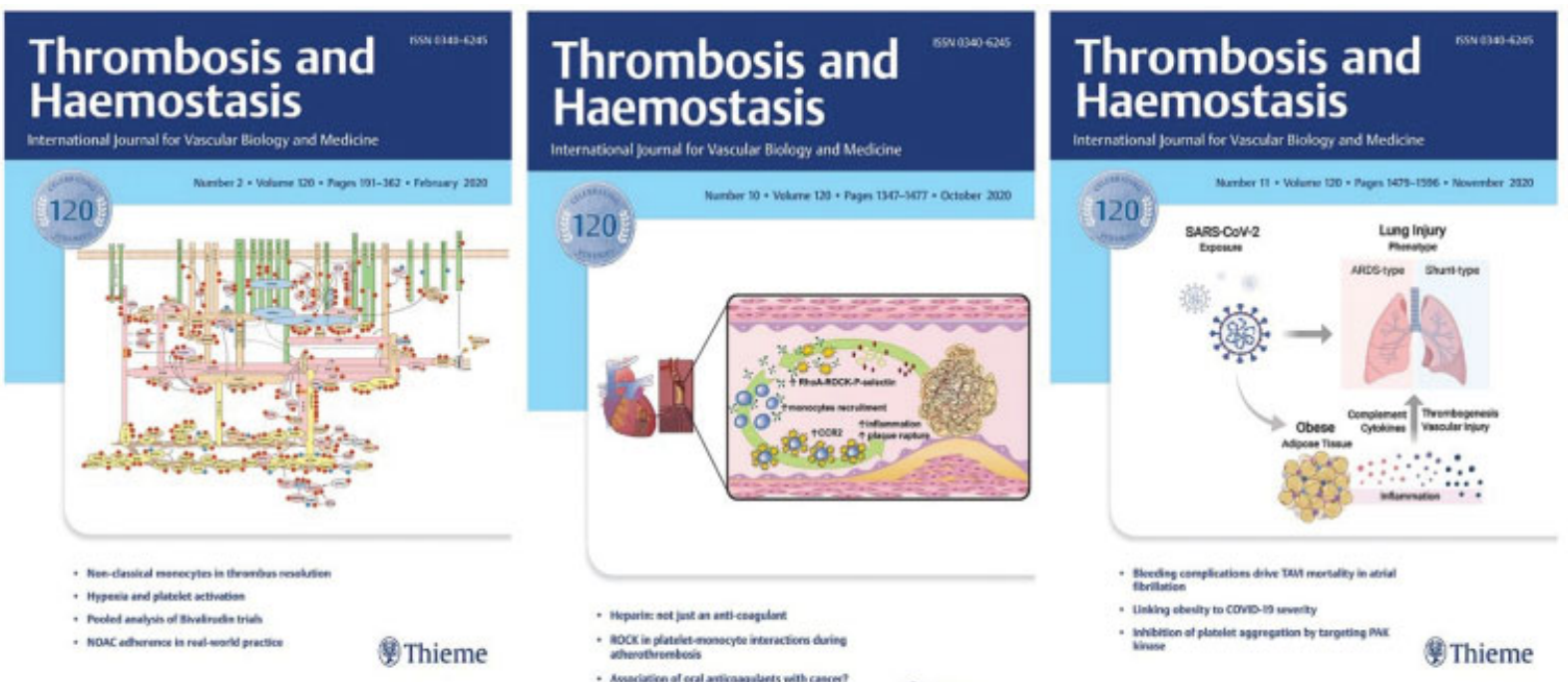

(2) Thieme
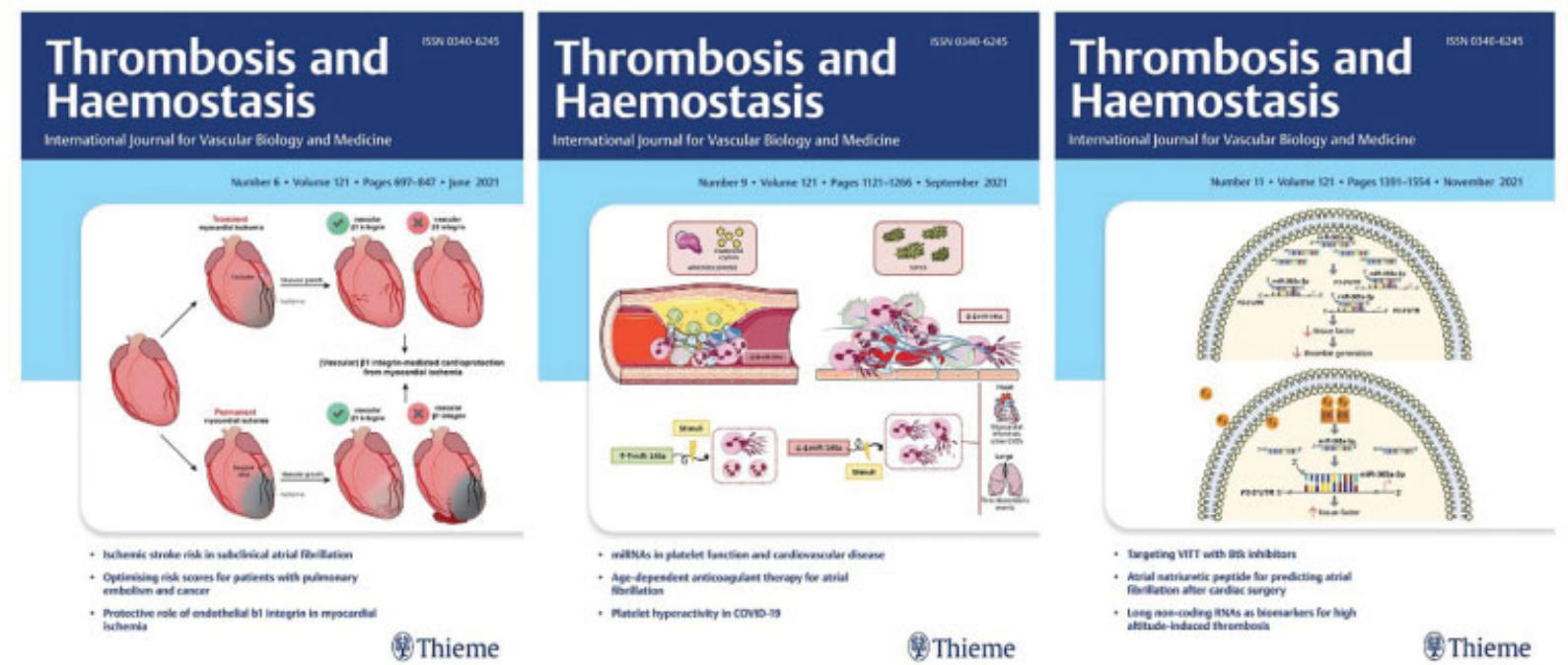

Fig. 2 Visual summaries, which have made the T\&H Cover in 2020 and 2021.

reading or by submitting quality investigations, as well as our section editors and reviewers, for putting their expert skills, reliability, and commitment to the service of $\mathrm{T} \& \mathrm{H}$.

As always, don't forget to follow us on social media:

\section{Follow us on Social Media!}
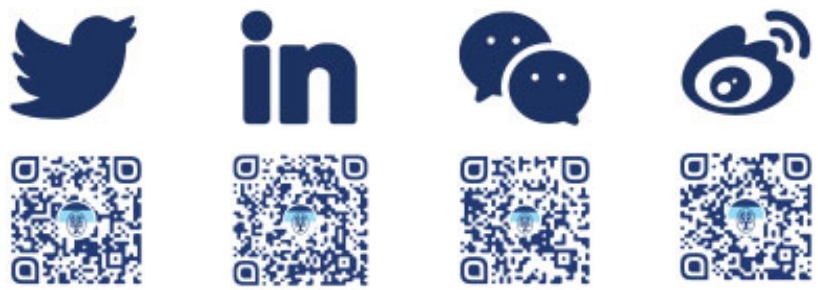

We are confident that your future contributions will respond to the undoubtedly coming challenges of 2022 and are looking forward to rising to these together.
Conflict of Interest

G.Y.H.L. reports consultancy and speaker fees from Bayer, Bayer/Janssen, BMS/Pfizer, Biotronik, Medtronic, Boehringer Ingelheim, Microlife, Roche, and Daiichi-Sankyo outside the submitted Work. No fees received personally.

\section{References}

1 Lip GYH, Rigby A, Weber C. Looking Back on 2020, Looking Forward to 2021. Thromb Haemost 2021;121(01):1-3

2 Weber C, Rigby A, Lip GYH. Thrombosis and Haemostasis 2020 Editors' Choice Papers. Thromb Haemost 2021;121(01):109-114

3 Weber CRA, Lip GYH. Thrombosis and Haemostasis 2021 Editors' Choice Papers. Thromb Haemost 2022;123(01):163-170

4 Henning C, Branopolski A, Follert P, et al. Endothelial $\beta 1$ integrinmediated adaptation to myocardial ischemia. Thromb Haemost 2021;121(06):741-754

5 Tian J, Adams MJ, Tay JWT, et al. Estradiol-responsive miR-365a$3 p$ interacts with tissue factor 3'UTR to modulate tissue factorinitiated thrombin generation. Thromb Haemost 2021;121(11): 1483-1496

6 Vilar R, Lukowski SW, Garieri M, Di Sanza C, Neerman-Arbez M, Fish RJ. Chemical modulators of fibrinogen production and their 
impact on venous thrombosis. Thromb Haemost 2021;121(04): 433-448

7 Aliotta A, Bertaggia Calderara D, Zermatten MG, Alberio L. Sodium-calcium exchanger reverse mode sustains dichotomous ion fluxes required for procoagulant COAT platelet formation. Thromb Haemost 2021;121(03):309-321

8 Yamashita A, Nishihira K, Gi T, et al. Pathological features of ruptured coronary plaque and thrombus interfaces: fibrin and von Willebrand factor as platelet scaffolds on rupture sites. Thromb Haemost 2021;121(02):234-241

9 Billett HH, Reyes-Gil M, Szymanski J, et al. Anticoagulation in COVID-19: effect of enoxaparin, heparin, and apixaban on mortality. Thromb Haemost 2020;120(12):1691-1699

10 de Jong A, Dirven RJ, Boender J, et al. Ex vivo improvement of a von Willebrand disease type $2 \mathrm{~A}$ phenotype using an allele-specific small-interfering RNA. Thromb Haemost 2020;120(11): 1569-1579

11 Hsu L-W, Chen P-W, Chang W-T, Lee WH, Liu PY. The role of ROCK in platelet-monocyte collaborative induction of thromboinflammation during acute coronary syndrome. Thromb Haemost 2020; 120(10):1417-1431

12 Fanikos J, Murwin D, Gruenenfelder F, et al. Global use of idarucizumab in clinical practice: outcomes of the RE-VECTO surveillance program. Thromb Haemost 2020;120(01):27-35

13 Akhmedov A, Montecucco F, Costantino S, et al. Cardiomyocytespecific JunD overexpression increases infarct size following ischemia/reperfusion cardiac injury by downregulating Sirt3. Thromb Haemost 2020;120(01):168-180

14 Paterson GG, Young JM, Willson JA, et al. Hypoxia modulates platelet purinergic signalling pathways. Thromb Haemost 2020; 120(02):253-261

15 Izquierdo I, Barrachina MN, Hermida-Nogueira L, et al. A comprehensive tyrosine phosphoproteomic analysis reveals novel components of the platelet CLEC-2 signaling cascade. Thromb Haemost 2020;120(02):262-276

16 Chueh T-H, Cheng Y-H, Chen K-H, Chien CT. Thromboxane A2 synthase and thromboxane receptor deletion reduces ischaemia/reperfusion-evoked inflammation, apoptosis, autophagy and pyroptosis. Thromb Haemost 2020;120(02):329-343

17 Tahir S, Wagner AH, Dietzel S, et al. Endothelial CD40 mediates microvascular von Willebrand factor-dependent platelet adhesion inducing inflammatory venothrombosis in ADAMTS13 knockout mice. Thromb Haemost 2020;120(03):466-476

18 Wan LM, Zhang SK, Li SB, et al. Heparanase facilitates PMA-induced megakaryocytic differentiation in K562 cells via interleukin 6/ STAT3 pathway. Thromb Haemost 2020;120(04):647-657

19 Hearn JI, Green TN, Chopra M, et al. N-methyl-D-aspartate receptor hypofunction in Meg-01 cells reveals a role for intracellular calcium homeostasis in balancing megakaryocytic-erythroid differentiation. Thromb Haemost 2020;120(04):671-686

20 Smadja DM, Chocron R, Rossi E, et al. Autoregulation of pulsatile bioprosthetic total artificial heart is involved in endothelial homeostasis preservation. Thromb Haemost 2020;120(09): 1313-1322

21 Gencer S, Lacy M, Atzler D, van der Vorst EPC, Döring Y, Weber C. Immunoinflammatory, thrombohaemostatic, and cardiovascular mechanisms in COVID-19. Thromb Haemost 2020;120(12): 1629-1641
22 Schulman S, Hu Y, Konstantinides S. Venous thromboembolism in COVID-19. Thromb Haemost 2020;120(12):1642-1653

23 Waite AAC, Hamilton DO, Pizzi R, Ageno W, Welters ID. Hypercoagulopathy in severe COVID-19: implications for acute care. Thromb Haemost 2020;120(12):1654-1667

24 Polzin A, Dannenberg L, Thienel M, et al. Noncanonical effects of oral thrombin and factor Xa inhibitors in platelet activation and arterial thrombosis. Thromb Haemost 2021;121(02):122-130

25 Huang J, Huang S, Ma Z, et al. Ibrutinib suppresses early megakaryopoiesis but enhances proplatelet formation. Thromb Haemost 2021;121(02):192-205

26 Potpara TS, Lip GYH, Blomstrom-Lundqvist C, et al. The 4S-AF Scheme (Stroke Risk; Symptoms; Severity of Burden; Substrate): a novel approach to in-depth characterization (rather than classification) of atrial fibrillation. Thromb Haemost 2021;121(03):270-278

27 Vayne C, Nguyen T-H, Rollin J, et al. Characterization of new monoclonal PF4-specific antibodies as useful tools for studies on typical and autoimmune heparin-induced thrombocytopenia. Thromb Haemost 2021;121(03):322-331

28 Garcia A, Dunoyer-Geindre S, Fish RJ, Neerman-Arbez M, Reny JL, Fontana P. Methods to investigate miRNA function: focus on platelet reactivity. Thromb Haemost 2021;121(04):409-421

29 Locke M, Longstaff C. Extracellular histones inhibit fibrinolysis through noncovalent and covalent interactions with fibrin. Thromb Haemost 2021;121(04):464-476

30 Basu MK, Massicano F, Yu L, et al. Exome sequencing identifies abnormalities in glycosylation and ANKRD36C in patients with immune-mediated thrombotic thrombocytopenic purpura. Thromb Haemost 2021;121(04):506-517

31 Atiq F, van de Wouw J, Sorop O, et al. Endothelial dysfunction, atherosclerosis, and increase of von Willebrand factor and factor VIII: a randomized controlled trial in swine. Thromb Haemost 2021;121(05):676-686

32 Schilling U, Dingemanse J, Dobrow M, et al. Insights from in vitro and clinical data to guide transition from the Novel P2Y12 antagonist selatogrel to clopidogrel, prasugrel, and ticagrelor. Thromb Haemost 2021;121(06):755-766

33 Arroyo AB, Águila S, Fernández-Pérez MP, et al. miR-146a in cardiovascular diseases and sepsis: an additional burden in the inflammatory balance? Thromb Haemost 2021;121(09):1138-1150

34 von Hundelshausen P, Lorenz R, Siess W, Weber C. Vaccineinduced immune thrombotic thrombocytopenia (VITT): targeting pathomechanisms with Bruton tyrosine kinase inhibitors. Thromb Haemost 2021;121(11):1395-1399

35 Gissler MC, Scherrer P, Anto-Michel N, et al. Deficiency of endothelial CD40 induces a stable plaque phenotype and limits inflammatory cell recruitment to atherosclerotic lesions in mice. Thromb Haemost 2021;121(11):1530-1540

36 Fabris E, Korjian S, Coller BS, et al. Pre-hospital antiplatelet therapy for STEMI patients undergoing primary percutaneous coronary intervention: what we know and what lies ahead. Thromb Haemost 2021;121(12):1562-1573

37 Wan J, Konings J, de Laat B, Hackeng TM, Roest M. Added value of blood cells in thrombin generation testing. Thromb Haemost 2021;121(12):1574-1587

38 Vaughan CJ, Cronin H, Ryan PM, Caplice NM. Obesity and COVID19: a Virchow's triad for the 21st century. Thromb Haemost 2020; 120(11):1590-1593 